Authors have nothing to disclose with regard to commercial support.



\section{OPERATOR EXPERTISE BETWEEN APPLES AND ORANGES OF THE MINI-STERN TRIAL \\ To the Editor:}

The Mini-Stern trial comparing mini-sternotomy (MS) and full sternotomy (FS) aortic valve replacement $(\mathrm{AVR})^{1}$ is timely in the context of increasing enthusiasm for minimally invasive AVR. The result was perhaps surprising in that the primary end point of length of stay was longer in MS compared with FS (9.5 vs 8.6 days), both of which are significantly longer than the Society of Thoracic Surgeons mean of 7.4 days for isolated $\mathrm{AVR} .{ }^{2}$ We question whether the reported results reflect a direct comparison of techniques themselves because of the stratified randomization technique used.

To compare clinical outcomes intrinsic to 2 techniques, the randomization must ensure that surgeon-level variability in technical expertise specific to each technique is distributed equally between the 2 treatment arms. The randomization was stratified at the surgeon level, which ensures equal proportion of each surgeon performing surgeries in both arms. However, this stratified randomization required all surgeons to perform both MS and FS AVR in equal proportions with an underlying assumption that the included surgeons were all as experienced in MS AVR as they were in FS AVR. The authors reported that "All participating surgeons were consultants experienced in performing AVR by both FS and MS,"1 which is not synonymous to all surgeons having the level of expertise in MS equivalent to that in FS (Figure 1). Attempts to compare a technically more demanding approach that is performed less often with a conventional one performed ubiquitously suffers from this potential bias in that surgeons are often less experienced in the less frequently performed approach that requires unique skill sets. Therefore, a direct comparison of techniques is difficult to achieve without a rigorous standardization of expertise

\footnotetext{
The Editor welcomes submissions for possible publication in the Letters to the Editor section that consist of commentary on an article published in the Journal or other relevant issues. Authors should: • Include no more than 500 words of text, three authors, and five references. • Type with double-spacing. • See http://jtcs.ctsnetjournals.org/ misc/ifora.shtml for detailed submission instructions. • Submit the letter electronically via jtcvs.editorialmanager.com. Letters commenting on an article published in the JTCVS will be considered if they are received within 6 weeks of the time the article was published. Authors of the article being commented on will be given an opportunity of offer a timely response ( 2 weeks) to the letter. Authors of letters will be notified that the letter has been received. Unpublished letters cannot be returned.
}

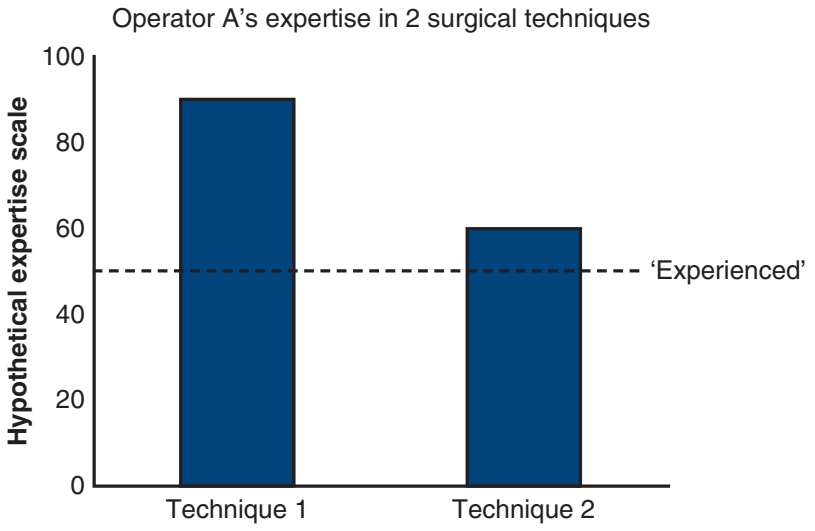

FIGURE 1. Hypothetical operator expertise in 2 surgical techniques. Potential discrepancy in the levels of proficiency in 2 techniques at a surgeon level above an arbitrary proficiency threshold.

in the operators, such as the minimum case volume requirement for participating surgeons used in CORONARY. $^{3}$ A potential for bias is strengthened by the presumption that it is extremely unlikely that any operator is less proficient in FS AVR than they are in MS AVR, while the reverse is probable.

At center level, excellence in one type of operation does not guarantee excellence in another. ${ }^{4}$ Because the equality in the level of technical expertise in each approach for all surgeons cannot be assessed adequately, we recommend cautious interpretation of the results as the comparison of outcomes intrinsic to 2 operative techniques.

In this sense, observational studies comparing these 2 techniques, which have indicated that MS AVR is associated with shorter intensive care unit length of stay and lower incidence of transfusion, ${ }^{5}$ offer value. Although the heterogeneity and selection bias inherent to observational studies limit interpretations, aggregated data from centers and surgeons specializing in minimally invasive approach offer complementary insights.

Makoto Mori, $M D$

Arnar Geirsson, MD

Section of Cardiac Surgery

Yale University School of Medicine

New Haven, Conn

\title{
References
}

1. Nair SK, Sudarshan CD, Thorpe BS, Singh J, Pillay T, Catarino P, et al. Mini-Stern Trial: a randomized trial comparing mini-sternotomy to full median sternotomy for aortic valve replacement. J Thorac Cardiovasc Surg. 2018;156:2124-32.

2. The Society of Thoracic Surgeons. STS measure - prolonged length of stay after valve procedures. Available at: https://www.sts.org/sites/default/files/files/PDF/ STS_ProlongedLengthofStayFollowing ValveSurgery.pdf. Accessed October 3, 2018.

3. Lamy A, Devereaux PJ, Prabhakaran D, Taggart DP, Hu S, Paolasso E, et al. Off-pump or on-pump coronary-artery bypass grafting at 30 days. $N$ Engl J Med. 2012;366:1489-97. 
4. Johnston LE, Downs EA, Hawkins R, Quader M, Speir A, Rich J, et al. Good at one or good at all? variability of coronary and valve operation outcomes within centers. Ann Thorac Surg. 2018;105:1678-83.

5. Kirmani BH, Jones SG, Malaisrie SC, Chung DA, Williams RJ. Limited versus full sternotomy for aortic valve replacement. Cochrane Database Syst Rev. 2017;4: Cd011793.

https://doi.org/10.1016/j.jtcvs.2018.10.001

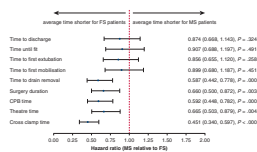

OBJECTIVE

ASSESSMENT

OF CLINICAL

BENEFIT WITH

MINISTERNOTOMY

MORE

\section{IMPORTANT THAN ANECDOTAL}

\section{CLINICAL EXPERIENCE OF SURGEONS}

\section{Reply to the Editor:}

I wish to thank Drs Mori and Geirsson for their critical comments regarding my group's manuscript on MiniStern Trial. Although at the outset I agree with some of their comments, I would like to address and explain some of their concerns about the conduct and findings of this trial.

This trial was conducted in the United Kingdom, where the national health care system (the National Health Service) is different from that in the United States. I therefore cannot comment as to why the duration of hospital stay in general is longer than the average duration of stay in the Society of Thoracic Surgeons database. In our study, however, we found that the average length of stay was slightly longer for patients in the ministernotomy (MS) group than in the full sternotomy (FS) group. In the United Kingdom, duration of hospital stay is influenced not only by medical factors but also by social factors related to patients.
We did not find any difference in duration of hospital stay between the groups, however, even when social reasons for delay in hospital discharge were excluded.

In the MiniStern Trial, fitness for discharge was assessed not only by the medical staff but also by physiotherapists who were independent of the trial. Nonrandomized observational studies are biased, because on many occasions discharge date is decided by the surgeon, who naturally will be keen to discharge patients early, thereby involuntarily inducing bias in the process.

The trial steering group had recommended and agreed on the standards of proctoring and training before surgeons recruited patients into this trial. The overall experience of surgeons in terms of number of FS and MS operations performed before recruitment into the trial is something that I agree is significantly different. In other words, surgeons were not performing aortic valve replacements in equal numbers through FS and MS before this trial. The rate of conversion of MS to FS in the trial, however, was under the accepted rate of $5 \%$. Patients undergoing MS did not have excessive mortality, either. The rate of immediate postoperative complications, namely bleeding, stroke, or paraprosthetic regurgitation, did not show any significant difference between the groups either. Of course, bypass and crossclamp times were significantly longer in the MS group than in the FS group. This is the situation in multiple publications, even when very experienced minimal access surgeons have performed MS operations. I therefore believe that the "relative inexperience" of the surgeons performing MS cannot be a significant cause leading to the observations of this trial. During the statistical analysis of data, surgeon was considered as an independent variable, but there was no statistical significance noted.

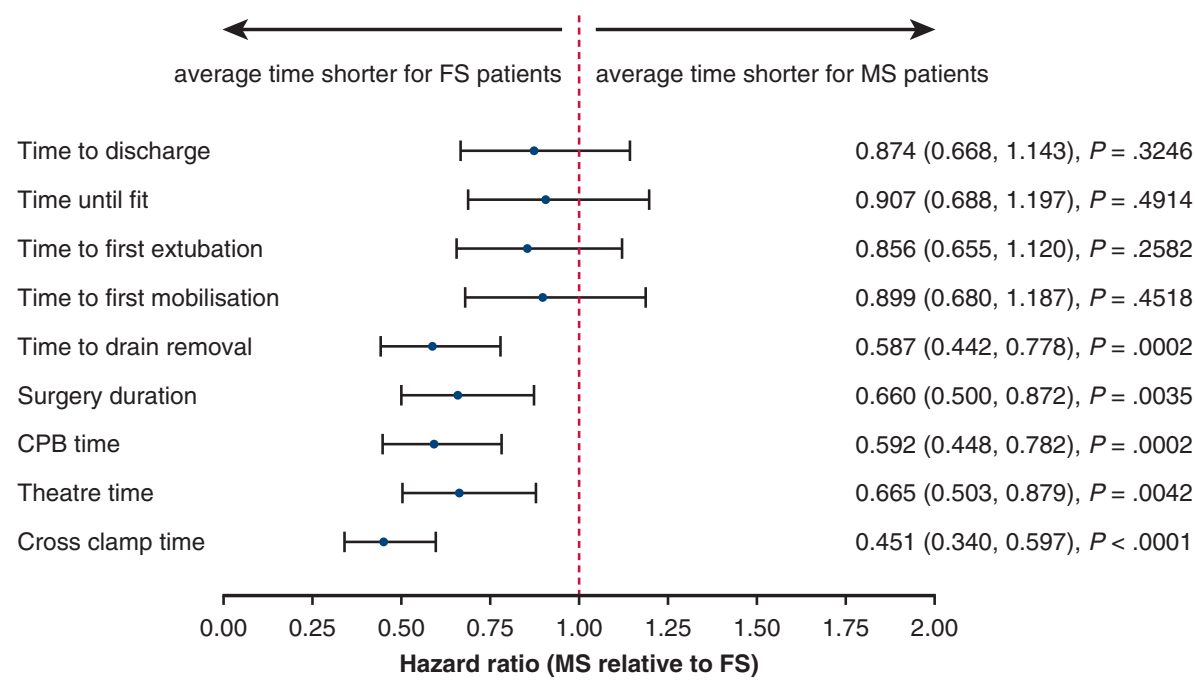

FIGURE 1. MiniStern Trial observations. $F S$, Full sternotomy; $M S$, ministernotomy; $C P B$, cardiopulmonary bypass. 